\title{
Biliary tract visualization using near-infrared imaging with indocyanine green during laparoscopic cholecystectomy: results of a systematic review
}

\author{
S. L. Vlek ${ }^{1}$ - D. A. van Dam ${ }^{1}$ - S. M. Rubinstein ${ }^{2}$ - E. S. M. de Lange-de Klerk ${ }^{2}$ • \\ L. J. Schoonmade ${ }^{3}$ J. B. Tuynman ${ }^{1}$. W. J. H. J. Meijerink ${ }^{1} \cdot$ M. Ankersmit ${ }^{1}$
}

Received: 13 June 2016/Accepted: 25 October 2016/Published online: 14 November 2016

(c) The Author(s) 2016. This article is published with open access at Springerlink.com

\begin{abstract}
Background Near-infrared imaging with indocyanine green (ICG) has been extensively investigated during laparoscopic cholecystectomy (LC). However, methods vary between studies, especially regarding patient selection, dosage and timing. The aim of this systematic review was to evaluate the potential of the near-infrared imaging technique with ICG to identify biliary structures during LC. Methods A comprehensive systematic literature search was performed. Prospective trials examining the use of ICG during LC were included. Primary outcome was biliary tract visualization. Risk of bias was assessed using ROBINS-I. Secondly, a meta-analysis was performed comparing ICG to intraoperative cholangiography (IOC) for identification of biliary structures. GRADE was used to assess the quality of the evidence.

Results Nineteen studies were included. Based upon the pooled data from 13 studies, cystic duct (Lusch et al. in $\mathbf{J}$ Endourol 28:261-266, 2014) visualization was 86.5\% (95\% CI 71.2-96.6\%) prior to dissection of Calot's triangle with a 2.5-mg dosage of ICG and 96.5\% (95\% CI 93.9-98.4\%) after dissection. The results were not
\end{abstract}

Electronic supplementary material The online version of this article (doi:10.1007/s00464-016-5318-7) contains supplementary material, which is available to authorized users.

S. L. Vlek

s.vlek@vumc.nl

1 Department of Surgery, VU University Medical Centre, De Boelelaan 1118, 1081 HV Amsterdam, The Netherlands

2 Epidemiology and Biostatistics, VU University, Amsterdam, The Netherlands

3 Medical Library, VU University, Amsterdam, The Netherlands appreciably different when the dosage was based upon bodyweight. There is moderate quality evidence that the $\mathrm{CD}$ is more frequently visualized using ICG than IOC (RR 1.16; 95\% CI 1.00-1.35); however, this difference was not statistically significant.

Conclusion This systematic review provides equal results for biliary tract visualization with near-infrared imaging with ICG during LC compared to IOC. Near-infrared imaging with ICG has the potential to replace IOC for biliary mapping. However, methods of near-infrared imaging with ICG vary. Future research is necessary for optimization and standardization of the near-infrared ICG technique.

Keywords Near-infrared imaging $\cdot$ ICG $\cdot$ Laparoscopic cholecystectomy $\cdot$ Biliary tract visualization .

Intraoperative cholangiography

Laparoscopic cholecystectomy (LC) is one of the most frequently performed surgical procedures worldwide $[2,3]$. The most serious complication is bile duct injury with an incidence $0.3-1.5 \%$ [4-6]. Bile duct injury has significant impact on quality of life and survival. Since the introduction of LC, prevention of complications has been a priority of surgeons [7]. To avoid complications such as bile duct injury, instruments have been developed to minimize risk. One of the strategies is the critical view of safety (CVS) during the dissection of the gallbladder according to Strasberg [8].

Despite introduction of CVS, the use of modern highresolution cameras and angled optics, the incidence of bile duct injury still remains $0.42 \%$ [9]. Most common causes of bile duct injury are poor identification of the biliary tract and inflammatory changes such as acute cholecystitis. To 
overcome risk of bile duct injury, extra intraoperative visualization techniques, such as intraoperative ultrasound and cholangiogram (IOC), have been introduced [10].

IOC is a technique that aids the surgeon to identify the biliary anatomy, possible common bile duct stones and anatomical variations during LC. The use of IOC is debateable. Advocates of the technique argue IOC should be used routinely during LC in order to avoid bile duct injury. Adversaries argue that the technique is not practically feasible, because additional trained staff is required during surgery [5]. Furthermore, incision of the cystic duct is required which could lead to possible bile duct injury. Also, IOC provides additional harmful radiation for the patient $[5,11,12]$. Another disadvantage is that partial dissection of Calot's triangle should be performed before IOC can be utilized and, therefore, bile duct injury can occur before IOC.

Recently, intraoperative visualization of the bile ducts using near-infrared light and the fluorescent dye indocyanine green (ICG) were introduced during cholecystectomy [13]. This technique provides real-time imaging of the biliary tract even before dissection of Calot's triangle.

ICG is an intravenously delivered agent, which when stimulated by near-infrared light $(700-900 \mathrm{~nm})$ provides fluorescent visualization of vascular and biliary structures. ICG is a water-soluble dye with peak spectral absorption at $800 \mathrm{~nm}$. After intravenous injection, ICG is bound to plasma proteins and, therefore, remains intravascular. ICG is metabolized almost exclusively by hepatic parenchymal cells and secreted into the bile. Peak concentration in the bile occurs between $30 \mathrm{~min}$ and $2 \mathrm{~h}$ after injection, whereas peak concentration in the arterial system is reached within 1-2 $\min$ [14].

Near-infrared imaging with ICG during LC has only recently been introduced $[15,16]$. Under near-infrared light, the biliary structures are fluorescently highlighted, potentially aiding anatomical identification and prevention of bile duct injury. Benefits of ICG include that it is less invasive and no incision of the cystic duct is required, nor is the patient exposed to radiation. Furthermore, ICG has the potential to identify the biliary tract before dissection of Calot's triangle, whereas IOC is generally performed after dissection of the $\mathrm{CD}$.

Currently, near-infrared imaging with ICG is rapidly expanding to other surgical areas. The use of near-infrared imaging with ICG for LC is suggested to be safe and feasible [17-19]. However, between the published studies there is wide variation in technical and procedure-related factors, such as dosage, timing of ICG administration and patient pathology.

Primary question of this systematic review is to evaluate how the near-infrared imaging technique with ICG is used during LC in order to identify biliary structures. Secondary questions include: what is the influence of dosage and timing on biliary tract visualization before and after dissection of Calot's triangle? What is the influence of obesity and gallbladder disease aetiology on biliary tract visualization? And does near-infrared imaging with ICG provide more frequent biliary tract visualization compared to IOC?

\section{Methods}

This systematic review was conducted in accordance with the preferred reporting items for systematic reviews and meta-analysis statement [20]. No approval of the medical ethics committee was required.

\section{Criteria for considering studies for this review}

\section{Eligibility criteria}

Articles were included if they fulfilled the following criteria: (1) the study describes the use of near-infrared imaging with ICG; (2) reports on laparoscopic cholecystectomies in humans for treatment of gallbladder disease (e.g. cholecystolithiasis and cholecystitis); and (3) used a prospective design (i.e. cohort study or randomized controlled trial). To avoid overlapping patient data in duplicate publications, the article with the largest sample size was included. No publication date or publication status restrictions were imposed. Only studies published in English, German or Dutch were included.

\section{Types of outcome measures}

Primary outcome of this review was extrahepatic biliary tract visualization of the cystic duct [1], common bile duct (CBD) and common hepatic duct (CHD) before and after dissection of Calot's triangle. Secondary outcomes were comparison of ICG to IOC, dosage and timing of administration of ICG and body mass index (BMI).

\section{Search methods for selection of studies}

\section{Electronic searches}

A comprehensive search was performed in the bibliographic databases PubMed, Embase.com, the Cochrane Library (via Wiley) and Web of Science from inception of the databases to the 8 February 2016, in collaboration with a medical librarian (LS). Search terms included controlled terms (Mesh in PubMed, Emtree in Embase) as well as free text terms. Free text terms were only used in the Cochrane Library and Web of Science. The following terms were used (including synonyms and closely related words) as 
index terms: 'biliary tract surgical procedures' or 'biliary tract' or 'biliary tract diseases' and 'cholangiography' or 'spectroscopy' or 'near-infrared' or 'surgery, computerassisted' and 'indocyanine green' or 'fluorescent dyes'. The full search strategies for all the databases are given in "Supplementary Information S1".

\section{Searching other sources}

Systematic reviews and narrative review articles that were identified during the search were checked for additional references.

\section{Data collection and analysis}

\section{Selection of studies}

Article selection was performed by three authors independent of one another (DvD, SV and MA). Titles and abstracts were first screened, and when unclear, the full text of an article was examined. In case of disagreement regarding inclusion or exclusion, a paper was discussed to establish consensus. To avoid overlapping patient data in duplicate publications, the article with the largest sample size was included. The process of inclusion is shown in a flow chart (Fig. 1).

\section{Data extraction and management}

Data were extracted by three authors (SV, DvD and MA) independent of one another using a data extraction form that included information on: publication details; dosage and timing of ICG administration; camera system used; general patient characteristics; general surgical procedure characteristics, including conversion and complication rate and operating time; LC indications and information on biliary tract visualization.

\section{Risk of bias assessment}

Two authors (SV and MA) assessed the risk of bias for studies that reported comparisons between ICG and IOC using the Cochrane's ROBINS-I tool (Risk Of Bias In Nonrandomized Studies of Interventions) [21]. The following items were assessed: bias due to confounding; selection bias; bias in measurement of interventions; bias due to missing data; bias in measurement of outcomes; and bias in the selection of the reported result. Each domain was scored as low, moderate, serious or critical risk of bias. Overall risk of bias of the included study was scored serious if serious risk of bias was scored in at least one domain. If no serious risk of bias was scored in any domain, the study would receive an overall moderate risk of bias.

\section{Measures of treatment effect}

The primary outcome is dichotomous (i.e. identification biliary structure). Prevalence of biliary duct visualization for the $\mathrm{CD}, \mathrm{CBD}, \mathrm{CHD}$ and the cystic duct junction $(\mathrm{CD}-\mathrm{j})$ is given as proportions. Weighted mean biliary duct visualization was calculated through pooled analysis in a random effects model with $95 \%$ confidence intervals using MedCalc software (Oostende, Belgium).

ICG visualization was compared to IOC for the $\mathrm{CD}$, $\mathrm{CBD}$ and $\mathrm{CHD}$. Outcomes are weighted by inverse variance in a random effects model. Treatment effect is presented as relative risk with $95 \%$ confidence intervals. These analyses were conducted in RevMan5 [22]. Heterogeneity between studies was assessed through a number of manners: Eye-Ball, $Q$ test and the $I^{2}$ statistic. Technical failure of IOC was not excluded from calculations, but analysed as not able to visualize the bile duct structures.

\section{Data synthesis}

The overall quality of the evidence and strength of recommendations was evaluated using GRADE [23]. At the start of GRADE assessment process, we assumed high quality for all studies and we downgraded the quality of the evidence for each comparison by one to two levels depending on the seriousness of the violations in each domain.

To assess the risk of bias for a comparison, the risk of bias tables for each study in that comparison was considered. For each comparison, the risk of bias was considered serious $(-1)$ if a majority of the evidence in the studies included in the meta-analysis (in terms of number of participants) scored serious risk of bias. For consistency, we considered a majority of the following four items: an $I^{2}$ value of more than 50\%, statistical significance of heterogeneity $(p<0.05)$, large variation in size effect and no overlapping of confidence intervals for downgrading $(-1)$. If half of the items were scored for inconsistency, the variation in size effect and confidence intervals were considered decisive. For imprecision of results, serious imprecision leading to downgrading $(-1)$ was judged if a comparison included fewer than 22,000 participants or if wide confidence intervals around the effect estimate were reported. Indirectness of the evidence was not an issue in this review, because the population, intervention, comparison and outcomes were directly correlated with the review question. Summary of Findings tables were generated for the primary analyses and for the primary outcome measures only. The quality of the evidence is described as: 


\section{PRISMA 2009 Flow Diagram}
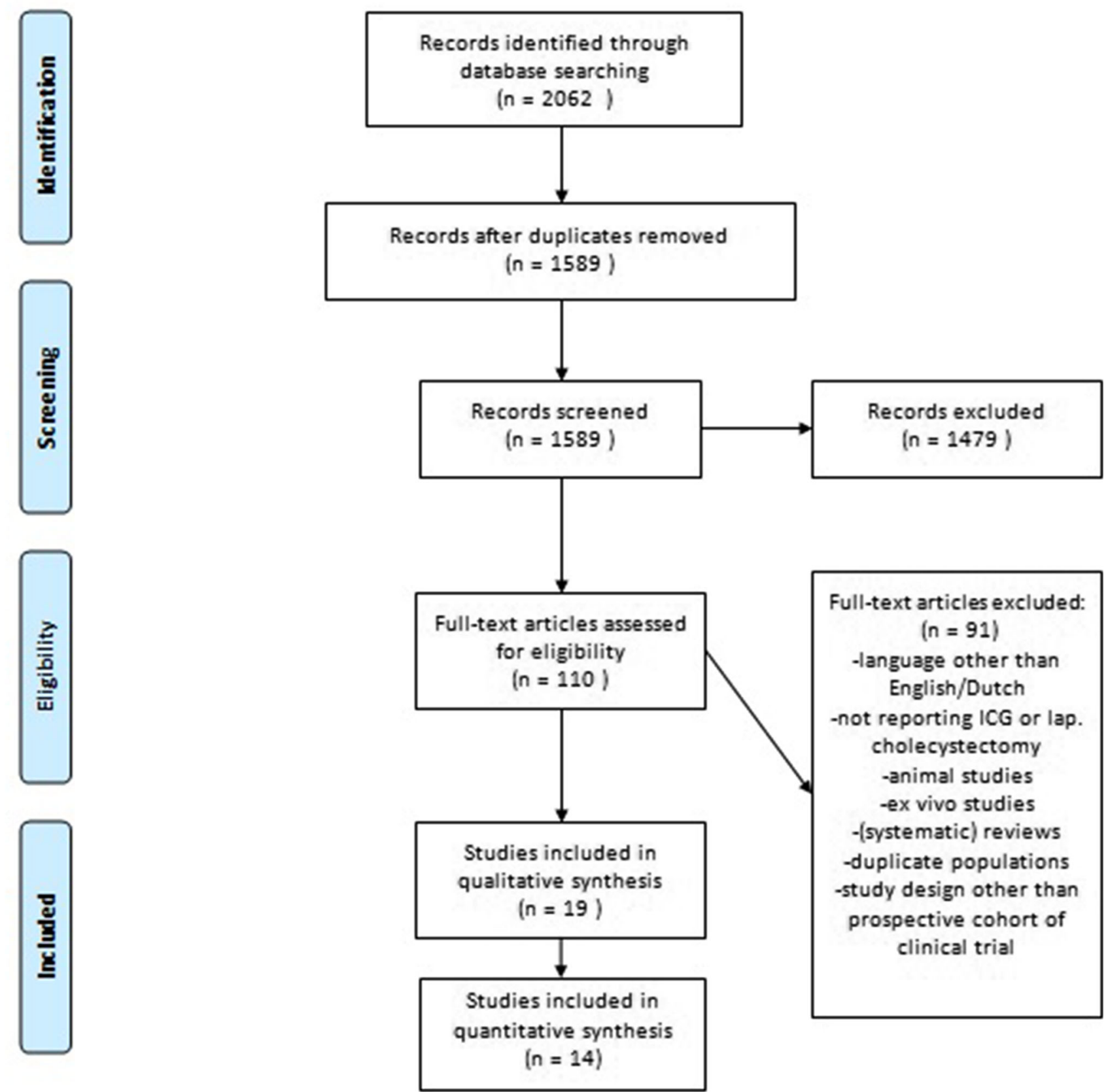

Fig. 1 PRISMA-flowchart of search strategy (8 February 2016)

- High: further research is very unlikely to change our confidence in the estimate of effect;

- Moderate: further research is likely to have an important impact on our confidence in the estimate of effect and may change the estimate;
- Low: further research is very likely to have an important impact on our confidence in the estimate of effect and is likely to change the estimate.

- Very low: the true effect is likely to be substantially different from the estimate of effect. 
A 'Summary of Findings' table was created using GRADEpro software [24].

\section{Results}

An overview of included studies is provided in Table 1. In total, 19 studies were included for qualitative evaluation. Of 19 studies [15, 16, 25-41], one non-randomized controlled trial was identified [27] and 18 prospective cohort studies. In total, 772 patients were reported, with a $0.5 \%$ (1/ 197 patients) conversion rate and $1.7 \%$ (10/578 patients) complication rate.

Of 19 studies, 13 reported near-infrared imaging with ICG during laparoscopic cholecystectomy [15, 16, 25, 28-30, 33-37, 40, 41] and six studies reported multiple laparoscopic techniques, including single incision and robotic surgery [26, 27, 31, 32, 38, 39].

Average time of first ICG administration varied between $74 \mathrm{~min}$ prior to surgery up to after tracheal intubation. Most studies administered ICG between 45 and $60 \mathrm{~min}$ prior to surgery. Timing of a second administration was reported on different moments during the surgical procedure in order to identify the cystic artery (CA). The CA was identified in $85.9 \%$ [SD 8.33] of the cases [32, 34, 37]. For near-infrared visualization, the use of six different camera systems has been reported.

In total, 14 studies included patients with only uncomplicated gallbladder disease (cholecystolithiasis, chronic cholecystitis or gallbladder polyp), encompassing 311 patients [15, 16, 26, 27, 30-32, 35, 37-41], and five studies included both complicated and uncomplicated gallbladder disease (acute cholecystitis, biliary pancreatitis, cholestasis and post-ERCP), encompassing 461 patients [25, 28, $29,33,34]$. In total, 78 of 461 patients suffered complicated gallbladder disease.

\section{Biliary tract visualization per dosage of ICG}

Several dosage schemes were used: a fixed dosage of $2.5 \mathrm{mg}$ ICG was used in nine studies [16, 26, 27, 31, 33, $35,37-39$ ], a dosage of $0.05 \mathrm{mg} / \mathrm{kg}$ bodyweight was used in six studies [28-30, 32, 34, 40], a dosage of $0.5 \mathrm{mg} / \mathrm{kg}$ bodyweight was used in two studies [25, 36] and two studies reported other dosage schemes [15, 41]. For analysis of biliary tract identification, the studies providing information on dosage scheme were stratified by fixed dosage $(2.5 \mathrm{mg})$ and dosage per kilogram bodyweight $(0.05 \mathrm{mg} / \mathrm{kg})$ as given in Table 2 .

Seven studies were stratified to the fixed dosage group encompassing 336 patients [16, 26, 31, 33, 35, 37, 38]. Six studies were stratified to the $0.05 \mathrm{mg} / \mathrm{kg}$ bodyweight group encompassing 274 patients [28-30, 32, 34, 40]. One study reported on visualization of the $\mathrm{CD}$ - $\mathrm{j}$ before dissection with positive identification in 35 of 35 cases [34]. No studies reported on the $\mathrm{CHD}$ and $\mathrm{CD}-\mathrm{j}$ visualization after dissection. Two studies have used a dosage scheme of $0.5 \mathrm{mg} / \mathrm{kg}$ bodyweight, of which one has evaluated visualization of the biliary structures before and after dissection in 23 patients [36]. Two included studies with different dosage schemes $[15,41]$ did not report on biliary tract visualization.

In addition to the $\mathrm{CD}, \mathrm{CBD}, \mathrm{CHD}$, other structures or aberrant anatomy were identified in $70 / 772(9.1 \%)$ of the patients. Mostly, the confluence of the right and left hepatic duct was visualized [16, 30, 34]. Other identified structures include: an extra CA [40], additional hepatic duct or aberrant course of the CD [16, 30, 34, 40] and a CBD cyst [30].

\section{ICG versus IOC visualization}

In total, four studies compared the use of ICG with IOC in 215 patients [29, 30, 35, 36]. Risk of bias was scored moderate for visualization of the $\mathrm{CD}$ and $\mathrm{CBD}$ and serious for visualization of the CHD (Table 3). Results of biliary structure visualization with ICG and IOC are presented in Fig. 2A-C. There is moderate quality evidence that visualization of the cystic duct with ICG is better than using the IOC (RR 1.16; 95\% CI 1.00-1.35), and, respectively, moderate and low quality evidence for the visualization of the CBD (RR 1.00; 95\% CI 0.97-1.03) and CHD (RR 0.76; 95\% CI 0.58-1.01)with ICG compared to visualization with IOC. None of the estimated effect sizes were statistically significant (Table 4). All three comparisons were downgraded for serious imprecision because few participants were examined. The comparison of the CHD also scored serious risk of bias due to possible selection bias.

\section{Obesity and visualization accuracy}

In addition to using BMI as a baseline characteristic, three studies reported on ICG visualization in different BMI groups [27, 28, 35]. Osayi et al. [35] reported similar visualization rates for the $\mathrm{CD}, \mathrm{CBD}$ and $\mathrm{CHD}$, but significantly increased visualization of the $\mathrm{CD}$ junction in the $\mathrm{BMI} \leq 30$ group $(p=0.038)$. Analysis of 20 patients with BMI $>35$ revealed prevalence of visualization of the CD and CBD of 91 and 64\%. Dip et al. [28] evaluated 71 patients of whom $53 \%$ had a BMI $>30$. They reported no statistically significant differences between obese (BMI > 30) and non-obese (BMI $\leq 30)$ patients for biliary tract visualization. Obesity was mentioned as a cause of failure of ICG visualization of bile ducts in one study [15].

Buchs et al. [27] noted a significant faster dissection in the ICG group compared to the control group (conventional laparoscopy) in patients with a $\mathrm{BMI}<25$. Biliary tract visualization was not assessed. 


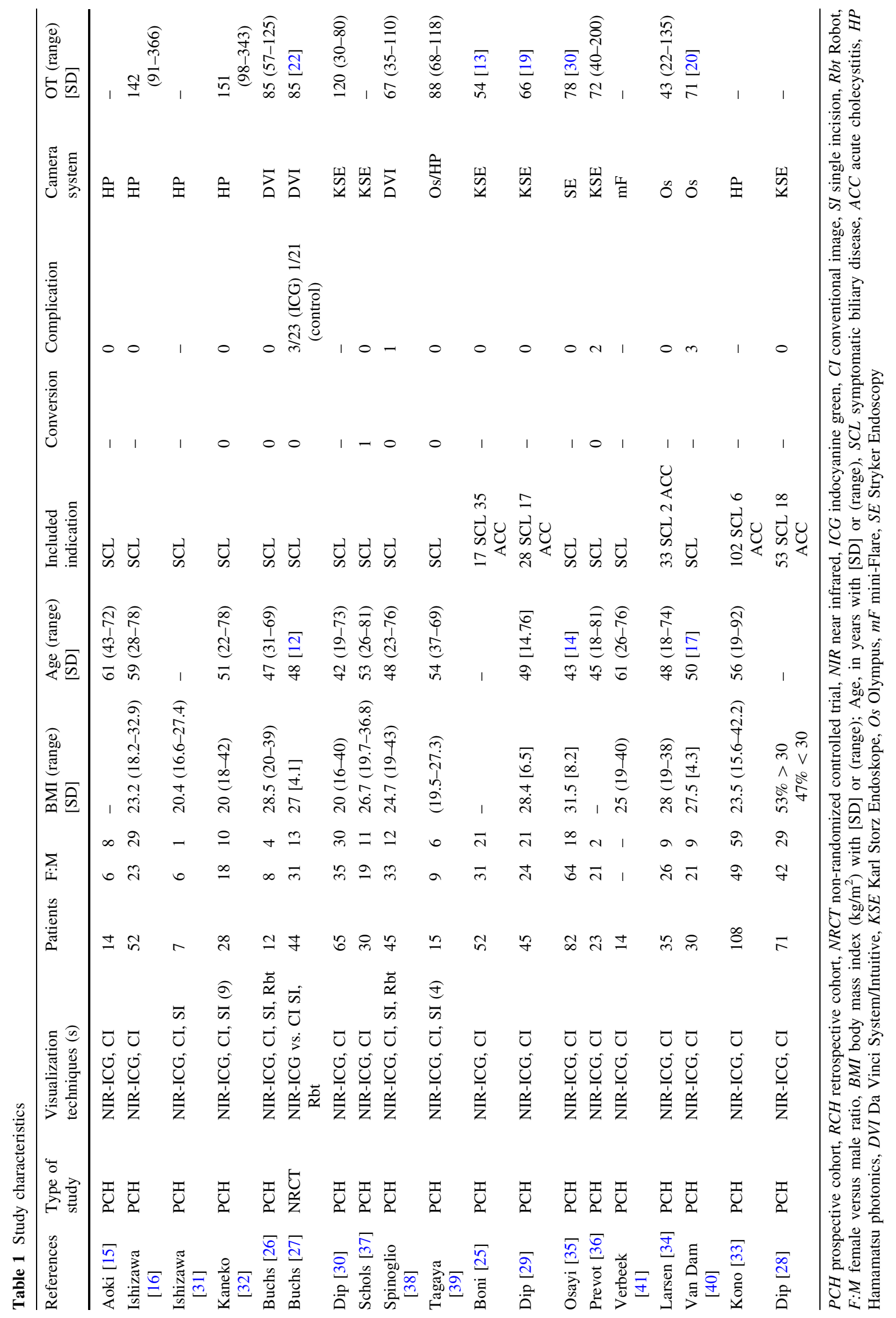


Table 2 Biliary tract visualization per dosage scheme

\begin{tabular}{|c|c|c|c|c|c|c|c|c|}
\hline Study & $n$ & $\begin{array}{l}\text { Adm. timing } \\
\text { (mins) }\end{array}$ & CD before & CD after & CBD before & CBD after & CHD before & CHD after \\
\hline \multicolumn{9}{|c|}{ Biliary tract visualization with a $2.5-\mathrm{mg}$ fixed dosage of ICG $n(\%)$} \\
\hline $\begin{array}{c}\text { Ishazawa } \\
{[16]}\end{array}$ & 52 & 30 & $52(100)$ & $52(100)$ & - & - & $50(96.2)$ & $52(100)$ \\
\hline $\begin{array}{c}\text { Ishazawa } \\
\text { [31] }\end{array}$ & 7 & $15^{\mathrm{a}}$ & $5(71.4)$ & - & - & - & $7(100)$ & - \\
\hline Buchs [26] & 12 & 45 & $11(91.7)$ & $12(100)$ & $6(50)$ & $10(83.3)$ & $4(33.3)$ & $8(66.7)$ \\
\hline Schols [37] & 30 & $15^{\mathrm{a}}$ & $29(96.7)$ & - & $25(83.3)$ & - & - & - \\
\hline $\begin{array}{l}\text { Spinoglio } \\
\text { [38] }\end{array}$ & 45 & 45 & $42(93.3)$ & $44(97.8)$ & $41(91.1)$ & $44(97.8)$ & 40 (88.9) & $44(97.8)$ \\
\hline Osayi [35] & 82 & 74 & $46(56.1)$ & $78(95.1)$ & $31(37.8)$ & $63(76.8)$ & $29(35.4)$ & $57(69.5)$ \\
\hline Kono [33] & 108 & - & $88(81.5)$ & $103(95.4)$ & - & & $94(87.0)$ & $100(92.6)$ \\
\hline Weighted mea & n $\%$ & $5 \% \mathrm{CI})$ & $\begin{array}{l}86.5 \\
\quad(71.2-96.6)\end{array}$ & $\begin{array}{l}96.5 \\
\quad(93.9-98.4)\end{array}$ & $\begin{array}{l}67.3 \\
\quad(35.5-92.1)\end{array}$ & $\begin{array}{l}86.6 \\
\quad(67.1-98.0)\end{array}$ & $\begin{array}{l}76.8 \\
\quad(51.2-94.7)\end{array}$ & $\begin{array}{l}88.9 \\
\quad(73.5-98.2)\end{array}$ \\
\hline \multicolumn{9}{|c|}{ Biliary tract visualization with a $0.05-\mathrm{mg}$ per $\mathrm{kg}$ bodyweight dosage of ICG $n(\%)$} \\
\hline Kaneko [32] & 28 & 15 & $26(92.8)$ & - & - & - & $27(96.4)$ & - \\
\hline Dip [30] & 65 & 60 & $50(76.9)$ & $65(100)$ & $50(76.9)$ & $65(100)$ & - & - \\
\hline Dip [29] & 45 & 60 & $44(97.8)^{\mathrm{b}}$ & - & $36(80.0)^{\mathrm{b}}$ & - & $27(60.0)^{\mathrm{b}}$ & - \\
\hline Larsen [34] & 35 & $15^{\mathrm{a}}$ & - & - & - & - & - & - \\
\hline $\begin{array}{c}\text { van Dam } \\
\text { [40] }\end{array}$ & 30 & $15^{\mathrm{a}}$ & $10(33.3)$ & $29(96.7)$ & $20(66.7)$ & $26(86.7)$ & - & - \\
\hline Dip [28] & 71 & 60 & $71(100)$ & - & $62(87.3)$ & - & $50(70.4)$ & - \\
\hline \multicolumn{3}{|c|}{ Weighted mean \% (95\% CI) } & $\begin{array}{l}85.2 \\
\quad(60.2-98.9)\end{array}$ & $\begin{array}{l}98.4 \\
\quad(92.4-99.9)\end{array}$ & $\begin{array}{l}78.7 \\
\quad(70.3-86.0)\end{array}$ & $\begin{array}{l}95.3 \\
\quad(73.4-99.0)\end{array}$ & $\begin{array}{l}76.6 \\
\quad(54.5-92.9)\end{array}$ & \\
\hline
\end{tabular}

Visualization per dosage group. Number of biliary structure identifications $n$ (\% proportion) before and after dissection of Calot's triangle. Timing of ICG administration is equal (average 37.3 and $37.5 \mathrm{~min}$ before surgery) for both groups

$I C G$ indocyanine green, timing timing of administration, mins minutes, $C D$ cystic duct, $C B D$ common bile duct, $C H D$ common hepatic duct

${ }^{\text {a }}$ ICG administration after anaesthesia

${ }^{\mathrm{b}}$ Biliary structure identification before and during dissection

Table 3 Risk of bias, ROBINS-I

\begin{tabular}{lllll}
\hline ROBINS-I & Dip [30] & Dip [46] & Osayi [35] & Prevot [36] \\
\hline $\begin{array}{l}\text { Participants } \\
\text { Domain }\end{array}$ & 65 & 45 & 82 & 23 \\
Bias due to confounding & Low & Low & Low & Low \\
Bias in selection of participants into the study & Low & Low & Serious & Serious \\
Bias in measurement of interventions & Low & Low & Low & Low \\
Bias due to departures from intended interventions & Low & Low & Low & Low \\
Bias due to missing data & Low & Low & Low & Low \\
Bias in measurement of outcomes & Moderate & Moderate & Moderate & Moderate \\
Bias in selection of the reported result & Low & Low & Low & Low \\
Overall & Moderate & Moderate & Serious & Serious \\
\hline
\end{tabular}

\section{Discussion}

This systematic review has examined the use of near-infrared imaging using ICG for visualization of the cystic duct and related structures. Results suggest that the use of the near-infrared imaging with ICG technique provides good overall visualization rates of the $\mathrm{CD}, \mathrm{CBD}, \mathrm{CHD}$ and
CD junction prior to and following dissection of Calot's triangle. Although the number of studies is limited and, therefore, the strength of our conclusions is also limited, visualization rates of the biliary structures using near-infrared imaging techniques with ICG appear to be equally good for either $2.5 \mathrm{mg}$ fixed dosage or $0.05 \mathrm{mg}$ per $\mathrm{kg}$ dosage of ICG. Small variation of timing of ICG 
A Meta-analysis of CD visualisation. ICG vs. IOC

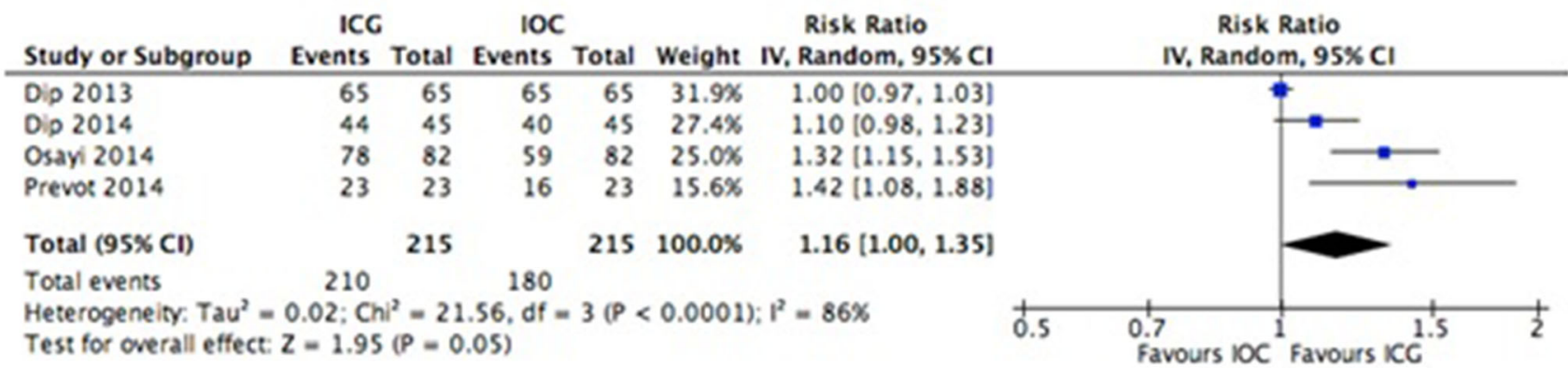

B Meta-analysis of CBD visualisation. ICG vs. IOC

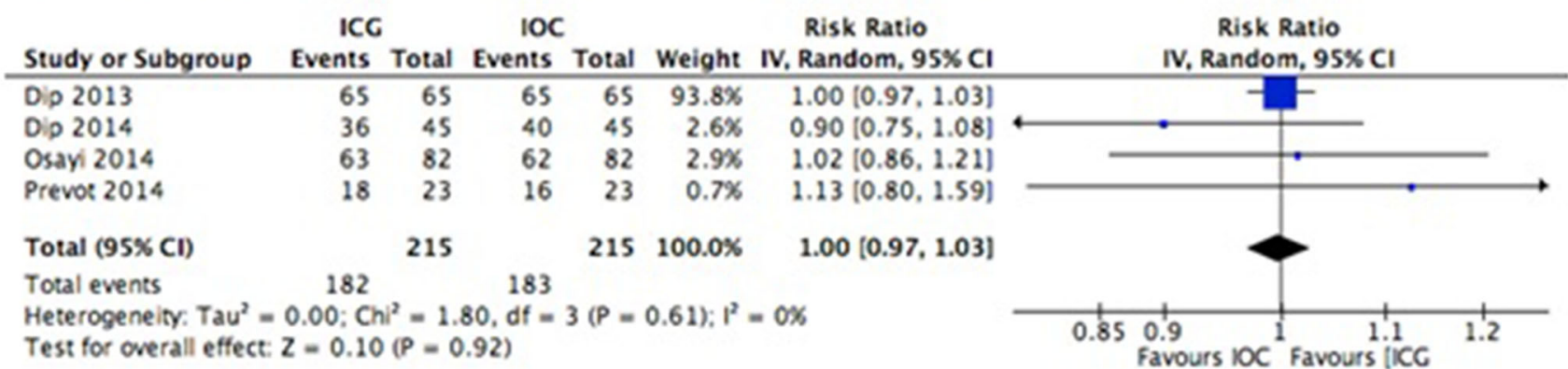

C Meta-analysis of CHD visualisation. ICG vs. IOC

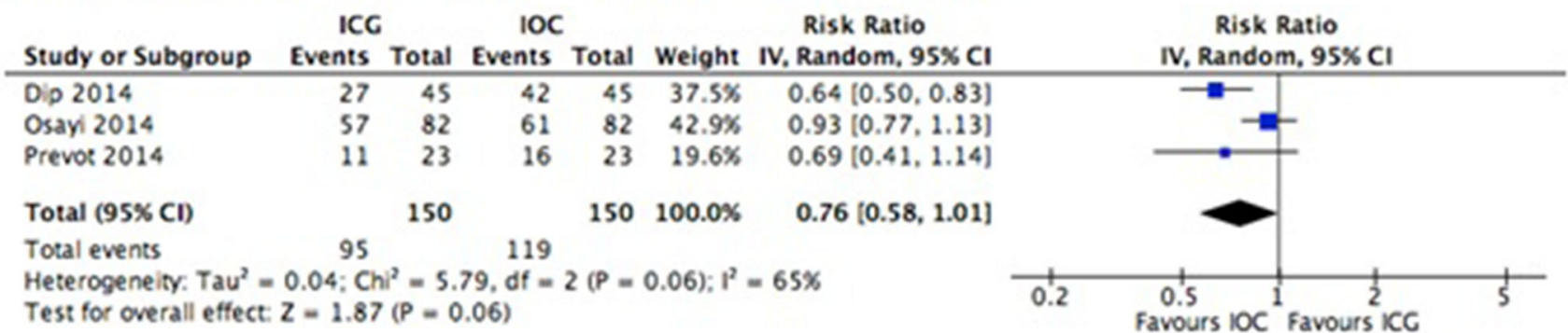

Fig. 2 A Meta-analysis of CD visualization. ICG versus IOC. B Meta-analysis of CBD visualization. ICG versus IOC. C Meta-analysis of CHD visualization. ICG versus IOC

administration was seen, varying between over an hour before surgery until directly after anaesthesia. As of yet, studies have revealed little information regarding influence of obesity or gallbladder disease aetiology on biliary tract visualization. Also, biliary tract visualization was comparable for near-infrared imaging with ICG and conventional IOC.

Most studies used similar timing of ICG administration. Only Kono et al. [33] described in their cohort a difference in visualization of the $\mathrm{CD}-\mathrm{j}$ after different administration times, with significantly more CD-j visualization after a longer preoperative administration of ICG (median $90 \mathrm{~min}$ prior to surgery (range 15-165) versus 47 min (range 21-205), $p<0.01)$. Verbeek et al. [41] described that administration of ICG $24 \mathrm{~h}$ prior to surgery results in a significantly increased CBD-to-liver contrast. Longer preoperative administration of ICG could result in increased visualization rates of the biliary tract structures.

An important factor that could influence ICG imaging is the amount of intra-abdominal adipose tissue. Unfortunately, too few studies have examined this aspect and; therefore, strong conclusions cannot be derived. Interestingly, one study [35] reported improved visualization rates for the CD-j in patients with lower BMI, while another study reported no differences [28] with increasing BMI. Intra-abdominal adipose tissue has been known to be a risk factor in abdominal surgery, leading to increased number of post-operative complications [42]. More intra- 
Table 4 GRADE summary of evidence

ICG compared to IOC for identification of the biliary ducts Patient or population: identification of the biliary ducts

Setting: VU University Medical Centre

Intervention: ICG

Comparison: IOC

\begin{tabular}{|c|c|c|c|c|c|}
\hline Outcomes & $\begin{array}{l}\text { Anticipated absolute } \\
\text { effects* }(95 \% \text { CI) } \\
\text { Risk with IOC }\end{array}$ & $\begin{array}{l}\text { Relative effect } \\
(95 \% \text { CI) } \\
\text { Risk with ICG }\end{array}$ & $\begin{array}{l}\text { No. of participants } \\
\text { (studies) }\end{array}$ & $\begin{array}{l}\text { Quality of the } \\
\text { evidence [22] }\end{array}$ & Comments \\
\hline \multirow[t]{2}{*}{ Cystic duct } & Study population & $\begin{array}{l}\text { RR } 1.16 \\
\quad(1.00-1.35)\end{array}$ & \multirow{2}{*}{$\begin{array}{l}430 \text { (four } \\
\text { observational } \\
\text { studies) }\end{array}$} & \multirow[t]{2}{*}{ Moderate $\mathrm{a}^{\mathrm{a}, \mathrm{b}, \mathrm{c}, \mathrm{d}, \mathrm{e}}$} & \multirow[t]{2}{*}{ Downgraded for imprecision } \\
\hline & 837 per 1000 & $\begin{array}{r}971 \text { per } 1000 \\
(837-1000)\end{array}$ & & & \\
\hline \multirow[t]{2}{*}{$\begin{array}{l}\text { Common bile } \\
\text { duct }\end{array}$} & Study population & $\begin{array}{l}\text { RR } 1.00 \\
\quad(0.97-1.03)\end{array}$ & \multirow{2}{*}{$\begin{array}{l}430 \text { (four } \\
\text { observational } \\
\text { studies) }\end{array}$} & \multirow[t]{2}{*}{ Moderate $\mathrm{e}^{\mathrm{e}, \mathrm{f}}$} & \multirow[t]{2}{*}{ Downgraded for imprecision } \\
\hline & 851 per 1000 & $\begin{array}{l}851 \text { per } 1000 \\
(826-877)\end{array}$ & & & \\
\hline \multirow[t]{2}{*}{$\begin{array}{l}\text { Common } \\
\text { hepatic duct }\end{array}$} & Study population & $\begin{array}{l}\text { RR } 0.76 \\
\quad(0.58-1.01)\end{array}$ & \multirow{2}{*}{$\begin{array}{l}300 \text { (three } \\
\text { observational } \\
\text { studies) }\end{array}$} & \multirow[t]{2}{*}{ Low $^{b, e, f, g}$} & \multirow[t]{2}{*}{$\begin{array}{l}\text { Downgraded for imprecision and } \\
\text { serious risk of bias }\end{array}$} \\
\hline & 793 per 1000 & $\begin{array}{l}603 \text { per } 1000 \\
(460-801)\end{array}$ & & & \\
\hline
\end{tabular}

*The risk in the intervention group (and its 95\% confidence interval) is based on the assumed risk in the comparison group and the relative effect of the intervention (and its $95 \% \mathrm{CI}$ )

CI: Confidence interval; RR: risk ratio

GRADE Working Group grades of evidence

High quality: we are very confident that the true effect lies close to that of the estimate of the effect

Moderate quality: we are moderately confident in the effect estimate that the true effect is likely to be close to the estimate of the effect, but there is a possibility that it is substantially different

Low quality: our confidence in the effect estimate is limited that the true effect may be substantially different from the estimate of the effect Very low quality: we have very little confidence in the effect estimate that the true effect is likely to be substantially different from the estimate of effect

a Test for heterogeneity $p<0.0001$

${ }^{2}>50 \%$

c Small variation in size effect

${ }^{\mathrm{d}}$ Overlapping of CI

e Two studies (Osayi/Prevot) include only patients with uncomplicated gallbladder disease

${ }^{\mathrm{f}} \mathrm{CI}$ crosses clinical decision threshold

g Selection bias

abdominal adipose tissue results in a decreased penetration of near-infrared light and thus decreased visualization of biliary tract structures [33]. BMI has been used as a standard for obesity because of its simplicity; however, BMI does not distinguish between the type of adipose tissue or location of fat within the intra-abdominal cavity [43, 44]. In order to assess the effects of intra-abdominal adipose tissue on near-infrared imaging with ICG, the patients should be selected on basis of fat percentage assessed by either CT or MRI instead of BMI [45].

There is moderate quality evidence comparing near-infrared imaging using ICG to conventional IOC; therefore, future research is likely to have an important impact on confidence in the estimate of effect and may change the estimate. However, since IOC comes with higher costs, more difficult perioperative logistics, greater radiation exposure, greater use of radiographic contrast fluids, frequent technical failure and risk of bile duct injury due to cannulation of the CD, ICG might be considered to be the better option for visualization of the biliary tract [46], although further research is necessary to confirm this recommendation.

As IOC depends on at least partial dissection in order to cannulate the $\mathrm{CD}$, ICG provides early imaging before start of dissection. Not only are early (prior to dissection) identification rates with ICG adequate, ICG can be used multiple times during dissection without increasing radiation or contrast load to the patient compared to IOC. Also, 
overall costs for ICG are 32.3 USD compared to 778.83 USD for IOC [46], although cost for the near-infrared imaging system is unclear.

Several studies have reported aberrant biliary anatomy with the use of ICG [16, 30, 34, 40]. Most commonly reported aberrant anatomy are variations in the hepatic duct. Failure to identify aberrant biliary anatomy could result in bile duct injury. In order to reduce major post-operative complications, ICG identification of aberrant anatomy might lead to a reduced rate of biliary tract leakages.

This systematic review is limited by the design of the included studies. Most included studies are prospective cohort studies and, therefore, highly subject to bias. To date, no randomized trials have been performed that investigate biliary tract visualization. The design of these prospective cohort studies is also limited because most studies did not compare intraoperative visualization with ICG to conventional white light laparoscopy. Therefore, no conclusions can be drawn whether the near-infrared with ICG technique provides advantages over conventional laparoscopy.

In addition, a rather heterogeneous population was examined. Some studies included only uncomplicated gallbladder disease, while others have included both complicated and uncomplicated disease. In the studies reporting both indications, biliary tract visualization results for both complicated and uncomplicated are pooled together. Furthermore, studies used different definitions for uncomplicated and complicated gallbladder disease. Therefore, no conclusions can be drawn on the use of biliary tract visualization for either complicated or uncomplicated gallbladder disease.

This systematic review and meta-analysis emphasize the need for further investigation. Randomized trials comparing near-infrared imaging with ICG to conventional white light laparoscopy are needed to assess the additive value of near-infrared imaging with ICG. Also, the effect of earlier preoperative ICG administration on biliary tract visualization should be further evaluated. To analyse the effect of uncomplicated and complicated gallbladder disease on ICG visualization results, further research should clearly define included patients groups.

\section{Conclusion}

This systematic review shows that near-infrared imaging with ICG provides good visualization of the biliary structures during LC. Visualization rates were equal for both dosage schemes. When compared to IOC, ICG provides equal visualization of the bile ducts before dissection. Near-infrared imaging with ICG has the potential to replace IOC for biliary mapping. However, future research is necessary for optimization and standardization of the near-infrared ICG technique.

\section{Compliance with ethical standard}

Disclosures S. Vlek, D. van Dam, S. Rubinstein, E. de Lange-de Klerk, L. Schoonmade, J. Tuynman, J. Meijerink and M. Ankersmit have no conflicts of interest or financial ties to disclose.

Open Access This article is distributed under the terms of the Creative Commons Attribution 4.0 International License (http://crea tivecommons.org/licenses/by/4.0/), which permits unrestricted use, distribution, and reproduction in any medium, provided you give appropriate credit to the original author(s) and the source, provide a link to the Creative Commons license, and indicate if changes were made.

\section{References}

1. Lusch A, Bucur PL, Menhadji AD, Okhunov Z, Liss MA, PerezLanzac A, McDougall EM, Landman J (2014) Evaluation of the impact of three-dimensional vision on laparoscopic performance. J Endourol 28:261-266

2. Gollan J, Bulkley PL, Diehl A (1993) NIH Consensus conference. Gallstones and laparoscopic cholecystectomy. JAMA 269: 1018-1024

3. Perissat J (1993) Laparoscopic cholecystectomy: the European experience. Am J Surg 165:444-449

4. Deziel DJ, Millikan KW, Economou SG, Doolas A, Ko ST, Airan MC (1993) Complications of laparoscopic cholecystectomy: a national survey of 4,292 hospitals and an analysis of 77,604 cases. Am J Surg 165:9-14

5. Flum DR, Dellinger EP, Cheadle A, Chan L, Koepsell T (2003) Intraoperative cholangiography and risk of common bile duct injury during cholecystectomy. JAMA 289:1639-1644

6. Giger U, Ouaissi M, Schmitz SF, Krahenbuhl S, Krahenbuhl L (2011) Bile duct injury and use of cholangiography during laparoscopic cholecystectomy. Br J Surg 98:391-396

7. McMahon AJ, Fullarton G, Baxter JN, O’Dwyer PJ (1995) Bile duct injury and bile leakage in laparoscopic cholecystectomy. $\mathrm{Br}$ J Surg 82:307-313

8. Strasberg SM, Hertl M, Soper NJ (1995) An analysis of the problem of biliary injury during laparoscopic cholecystectomy. J Am Coll Surg 180:101-125

9. Nuzzo G, Giuliante F, Giovannini I, Ardito F, D'Acapito F, Vellone M, Murazio M, Capelli G (2005) Bile duct injury during laparoscopic cholecystectomy: results of an Italian national survey on 56591 cholecystectomies. Arch Surg 140:986-992

10. Aziz O, Ashrafian H, Jones C, Harling L, Kumar S, Garas G, Holme T, Darzi A, Zacharakis E, Athanasiou T (2014) Laparoscopic ultrasonography versus intra-operative cholangiogram for the detection of common bile duct stones during laparoscopic cholecystectomy: a meta-analysis of diagnostic accuracy. Int $\mathbf{J}$ Surg 12:712-719

11. Ausania F, Holmes LR, Ausania F, Iype S, Ricci P, White SA (2012) Intraoperative cholangiography in the laparoscopic cholecystectomy era: why are we still debating? Surg Endosc 26:1193-1200

12. Ford JA, Soop M, Du J, Loveday BP, Rodgers M (2012) Systematic review of intraoperative cholangiography in cholecystectomy. Br J Surg 99:160-167

13. Oddi A, Di Nicola V, Panzini A, Berni A, Lucci S, Greco L, Urciuoli P, Custureri F (1996) The intraoperative visualization of 
the bile ducts by the use of fluorescent substances. A feasibility study. G Chir 17:620-623

14. Alander JT, Kaartinen I, Laakso A, Patila T, Spillmann T, Tuchin VV, Venermo M, Valisuo P (2012) A review of indocyanine green fluorescent imaging in surgery. Int $\mathrm{J}$ Biomed Imaging 2012:940585

15. Aoki T, Murakami M, Yasuda D, Shimizu Y, Kusano T, Matsuda K, Niiya T, Kato H, Murai N, Otsuka K, Kusano M, Kato T (2010) Intraoperative fluorescent imaging using indocyanine green for liver mapping and cholangiography. J Hepatobiliary Pancreat Sci 17(5):590-594

16. Ishizawa T, Bandai Y, Ijichi M, Kaneko J, Hasegawa K, Kokudo N (2010) Fluorescent cholangiography illuminating the biliary tree during laparoscopic cholecystectomy. $\mathrm{Br} \quad \mathrm{J}$ Surg 97:1369-1377

17. Schnelldorfer T, Jenkins RL, Birkett DH, Georgakoudi I (2015) From shadow to light: visualization of extrahepatic bile ducts using image-enhanced laparoscopy. Surg Innov 22:194-200

18. Schols RM, Connell NJ, Stassen LP (2015) Near-infrared fluorescence imaging for real-time intraoperative anatomical guidance in minimally invasive surgery: a systematic review of the literature. World J Surg 39:1069-1079

19. Scroggie DL, Jones C (2014) Fluorescent imaging of the biliary tract during laparoscopic cholecystectomy. Ann Surg Innov Res $8: 5$

20. Moher D, Liberati A, Tetzlaff J, Altman DG, Group P (2009) Preferred reporting items for systematic reviews and meta-analyses: the PRISMA statement. BMJ 339:b2535

21. Thomson H, Sterne J, Higgins J (2015) ACROBAT-NRSi (A cochrane risk of bias assessment tool: for non-randomized studies of interventions) for non-clinical community based studies: a participatory workshop using a worked example from public health. Abstracts of the 23rd Cochrane Colloquium

22. Kishi K, Fujiwara Y, Yano M, Inoue M, Miyashiro I, Motoori M, Shingai T, Gotoh K, Takahashi H, Noura S, Yamada T, Ohue M, Ohigashi H, Ishikawa O (2012) Staging laparoscopy using ALAmediated photodynamic diagnosis improves the detection of peritoneal metastases in advanced gastric cancer. J Surg Oncol 106:294-298

23. Guyatt GH, Oxman AD, Vist GE, Kunz R, Falck-Ytter Y, Alonso-Coello P, Schunemann HJ, Group GW (2008) GRADE: an emerging consensus on rating quality of evidence and strength of recommendations. BMJ 336:924-926

24. Kondo Y, Murayama Y, Konishi H, Morimura R, Komatsu S, Shiozaki A, Kuriu Y, Ikoma H, Kubota T, Nakanishi M, Ichikawa D, Fujiwara H, Okamoto K, Sakakura C, Takahashi K, Inoue K, Nakajima M, Otsuji E (2014) Fluorescent detection of peritoneal metastasis in human colorectal cancer using 5-aminolevulinic acid. Int $\mathrm{J}$ Oncol 45:41-46

25. Boni L, David G, Mangano A, Dionigi G, Rausei S, Spampatti S, Cassinotti E, Fingerhut A (2015) Clinical applications of indocyanine green (ICG) enhanced fluorescence in laparoscopic surgery. Surg Endosc 29(7):2046-2055

26. Buchs NC, Hagen ME, Pugin F, Volonte F, Bucher P, Schiffer E, Morel P (2012) Intra-operative fluorescent cholangiography using indocyanin green during robotic single site cholecystectomy. Int J Med Robot 8:436-440

27. Buchs NC, Pugin F, Azagury DE, Jung M, Volonte F, Hagen ME, Morel P (2013) Real-time near-infrared fluorescent cholangiography could shorten operative time during robotic single-site cholecystectomy. Surg Endosc Other Interv Tech 27(10):3897-3901

28. Dip F, Nguyen D, Montorfano L, Noste MES, Menzo EL, Simpfendorfer C, Szomstein S, Rosenthal R (2015) Accuracy of near infrared-guided surgery in morbidly obese subjects undergoing laparoscopic cholecystectomy. Obes Surg 26(3):525-530
29. Dip F, Roy M, Menzo EL, Simpfendorfer C, Szomstein S, Rosenthal RJ (2014) Routine use of fluorescent incisionless cholangiography as a new imaging modality during laparoscopic cholecystectomy. Surg Endosc 29(6):1621-1626

30. Dip FD, Nahmod M, Alle L, Sarotto L, Anzorena FS, Ferraina P (2013) Fluorescence cholangiography in laparoscopic cholecystectomy experience in Argentina. Front Gastr Res 31:80-85

31. Ishizawa T, Kaneko J, Inoue Y, Takemura N, Seyama Y, Aoki T, Beck Y, Sugawara Y, Hasegawa K, Harada N, Ijichi M, Kusaka K, Shibasaki M, Bandai Y, Kokudo N (2011) Application of fluorescent cholangiography to single-incision laparoscopic cholecystectomy. Surg Endosc 25:2631-2636

32. Kaneko J, Ishizawa T, Masuda K, Kawaguchi Y, Aoki T, Sakamoto Y, Hasegawa K, Sugawara Y, Kokudo N (2012) Indocyanine green reinjection technique for use in fluorescent angiography concomitant with cholangiography during laparoscopic cholecystectomy. Surg Laparosc Endosc Percutaneous Tech 22:341-344

33. Kono Y, Ishizawa T, Tani K, Harada N, Kaneko J, Saiura A, Bandai Y, Kokudo N (2015) Techniques of fluorescence cholangiography during laparoscopic cholecystectomy for better delineation of the bile duct anatomy. Medicine 94:1-9

34. Larsen SS, Schulze S, Bisgaard T (2014) Non-radiographic intraoperative fluorescent cholangiography is feasible. Dan Med J 61:A4891

35. Osayi SN, Wendling MR, Chaudhry UI, Drosdeck JM, Perry KA, Noria SF, Hazey JW, Muscarella P, Melvin WS, Narula VK (2014) Near infrared fluorescent cholangiography facilitates identification of biliary anatomy during laparoscopic cholecystectomy. Surg Endosc Other Interv Tech 28:267

36. Prevot F, Rebibo L, Cosse C, Browet F, Sabbagh C, Regimbeau J-M (2014) Effectiveness of intraoperative cholangiography using indocyanine green (versus contrast fluid) for the correct assessment of extrahepatic bile ducts during day-case laparoscopic cholecystectomy. J Gastrointest Surg 18(8):1462-1468

37. Schols RM, Bouvy ND, van Dam RM, Masclee AA, Dejong CH, Stassen LP (2013) Combined vascular and biliary fluorescence imaging in laparoscopic cholecystectomy. Surg Endosc 27:4511-4517

38. Spinoglio G, Priora F, Bianchi PP, Lucido FS, Licciardello A, Maglione V, Grosso F, Quarati R, Ravazzoni F, Lenti LM (2013) Real-time near-infrared (NIR) fluorescent cholangiography in single-site robotic cholecystectomy (SSRC): a single-institutional prospective study. Surg Endosc 27:2156-2162

39. Tagaya N, Sugamata $Y$, Makino N, Saito K, Okuyama T, Koketsu S, Oya M (2013) Fluorescence cholangiography in laparoscopic cholecystectomy: experience in Japan. Front Gastr Res 31:73-79

40. van Dam DA, Ankersmit M, van de Ven P, van Rijswijk AS, Tuynman JB, Meijerink WJ (2015) Comparing near-infrared imaging with indocyanine green to conventional imaging during laparoscopic cholecystectomy: a prospective crossover study. J Laparoendosc Adv Surg Tech Part A 25(6):486-492

41. Verbeek FP, Schaafsma BE, Tummers QR, van der Vorst JR, van der Made WJ, Baeten CI, Bonsing BA, Frangioni JV, van de Velde CJ, Vahrmeijer AL, Swijnenburg RJ (2014) Optimization of near-infrared fluorescence cholangiography for open and laparoscopic surgery. Surg Endosc 28:1076-1082

42. Morris K, Tuorto S, Gonen M, Schwartz L, DeMatteo R, D'Angelica M, Jarnagin WR, Fong Y (2010) Simple measurement of intra-abdominal fat for abdominal surgery outcome prediction. Arch Surg 145:1069-1073

43. Deurenberg P, Andreoli A, Borg P, Kukkonen-Harjula K, de Lorenzo A, van Marken Lichtenbelt WD, Testolin G, Vigano R, Vollaard N (2001) The validity of predicted body fat percentage from body mass index and from impedance in samples of five European populations. Eur J Clin Nutr 55:973-979 
44. Rothman KJ (2008) BMI-related errors in the measurement of obesity. Int J Obes (Lond) 32(Suppl 3):S56-S59

45. Yoshizumi T, Nakamura T, Yamane M, Islam AHMW, Menju M, Yamasaki K, Arai T, Kotani K, Funahashi T, Yamashita S, Matsuzawa Y (1999) Abdominal fat: standardized technique for measurement at CT. Radiology 211:283-286
46. Dip FD, Asbun D, Rosales-Velderrain A, Lo Menzo E, Simpfendorfer CH, Szomstein S, Rosenthal RJ (2014) Cost analysis and effectiveness comparing the routine use of intraoperative fluorescent cholangiography with fluoroscopic cholangiogram in patients undergoing laparoscopic cholecystectomy. Surg Endosc 28:1838-1843 